\title{
IN-SITU EXPOSURE ASSESSMENT OF
}

\section{INTERMEDIATE FREQUENCY FIELDS OF}

\section{DIVERSE DEVICES}

Matthias Van Den Bossche*, Leen, Verloock*, Sam, Aerts*, Wout, Joseph*, Luc, Martens* (email:wout.joseph@intec.UGent.be, fax:+32 933 14899)

*Department of Information Technology, Ghent University / iMinds, Gaston Crommenlaan 8, box 201, B-9050 Ghent, Belgium 
Abstract- In-situ exposure assessment of both electric and magnetic fields of different intermediate frequency sources is investigated. We investigated smart boards and touchscreens, energy saving bulbs, fluorescent lamps, a portable hearing unit, and an electrosurgical unit. For most of these sources, the electric field is the dominating quantity. ICNIRP reference levels are exceeded for touchscreens (44 kHz: up to $155.7 \mathrm{~V} / \mathrm{m}$ at $5 \mathrm{~cm}$ ), energy saving bulbs (38-52 $\mathrm{kHz}$ : up to $117.3 \mathrm{~V} / \mathrm{m})$, fluorescent lamps (52 kHz: up to $471 \mathrm{~V} / \mathrm{m}$ at $5 \mathrm{~cm}$ ) and electrosurgical units ESU (up to $920 \mathrm{kHz:} 792 \mathrm{~V} / \mathrm{m}$ at $0.5 \mathrm{~cm}$ ). Magnetic-field strengths up to $1.8 \mathrm{~A} / \mathrm{m}$ and $10.5 \mathrm{~A} / \mathrm{m}$ were measured close to the ESU and portable hearing unit $(69 \mathrm{~V} / \mathrm{m})$, respectively. Large differences of measured field values exist among the various operating modes of the IF equipment. Compliance distances for general public range from $15.3 \mathrm{~cm}$ (touchscreen) up to $25 \mathrm{~cm}$ (fluorescent lamps).

Key Words- intermediate frequency, IF, electromagnetic exposure, exposure of general public, occupational exposure, measurement, smart board, touchscreen, energy saving light bulb, fluorescent lamp, portable hearing unit, electrosurgical unit

\section{INTRODUCTION}

Exposure assessment of non-ionizing radiation in the intermediate frequency (IF) range between $300 \mathrm{~Hz}$ and $10 \mathrm{MHz}$ is rarely investigated. Up to now, exposure research focus was on the extreme low frequencies (ELF) and radio frequencies (RF). Examples of sources producing IF exposures are amongst others ${ }^{(1)}$ : light bulbs, electronic article surveillance (EAS) systems, nondirectional beacons (NDB), induction cookers, and electrosurgical units. These devices are omnipresent in our environment and the use of them is increasing. The World Health 
Organization (WHO) recommended that IF exposure needed to be better characterized ${ }^{(2)}$. Also the European Union Research and Innovation FP7 research call ENV.2013.6.4-2 addressed specifically the importance of investigating IF fields.

Exposure in close proximity to these IF devices is important and often very localized. Electronic article surveillance (EAS) systems were investigated in Refs. $(3,4,6)$ and it was reported that the reference levels of the International Commission on Non-Ionizing Radiation Protection $(\operatorname{ICNIRP})^{(7,8)}$ were exceeded for several of the investigated EAS systems. Also fields from fluorescent lights and energy saving bulbs ${ }^{(9,10)}$, domestic or professional induction cookers ${ }^{(6,11,12)}$, non-direction beacon (NDB) systems ${ }^{(13,14)}$, and electrosurgical units ${ }^{(6,15,16,17)}$ exceeded the reference levels. Induction cookers can even exceed the ICNIRP basic restrictions by a factor of $16^{(11)}$. Floderus et al. ${ }^{(6)}$ investigated induction furnaces and heaters, surface treatment equipment, EAS, and medical devices for surgery and muscle stimulation. There is a lack of publications about the electromagnetic fields within less than $30 \mathrm{~cm}$ distance from fluorescent lamps ${ }^{(9)}$. Some publications mention IF exposure from devices up to $30 \mathrm{MHz}^{(18)}$, but these devices will not be considered here.

The objective of this paper is to perform in-situ assessment of both the electric and magnetic fields of different IF sources, located in home and school environments, in ticket offices (counters), and hospitals. To this end, measurements with spectral measurement equipment and suitable probes were performed. Here, we focus on smart boards and large touchscreens for educational purposes, energy saving light bulbs, fluorescent lamps, portable hearing units, and electrosurgical units. Up to now, some of these devices (smart boards, hearing units) have not often been investigated from an exposure point of view, according to the authors' knowledge. Also measurements as a function of the separation from these devices were performed to 
determine compliance distances, outside which the field levels do not exceed the ICNIRP reference levels. For the portable hearing units, and electrosurgical units, different operational modes are possible for which IF exposure is evaluated. The results of this study are of importance for authorities and international organizations (WHO) as it is important to quantify the IF exposure.

\section{MATERIALS AND METHOD}

\section{A. Configuration and sources}

Table 1 lists the investigated IF sources, their corresponding identified frequencies (see further) and the corresponding ICNIRP reference levels ${ }^{(8)}$ (2010, general public and occupational exposure) for the electric fields $\mathrm{E}(\mathrm{V} / \mathrm{m})$ and magnetic fields $\mathrm{H}(\mathrm{A} / \mathrm{m})$. Also the number of measurements is listed. The following sources were considered: (i) a touchscreen (touchportal of Packard Bell) for educational purposes in a school, (ii) smart board (digital school board, Prowise), (iii) energy saving bulbs (compact fluorescent lamps CFL), (iv) fluorescent lamps, (v) a portable hearing unit with different modes (i.e., a portable induction loop system that amplifies the sound for "hard of hearing persons", used at ticket offices and counters), and (vi) an electrosurgical unit (ESU) with different modes. The measurements were performed from June 2012 to July 2013 and occurred in homes, school environments, in ticket offices (counters), and hospitals. We will discuss here the IF exposure due to these sources and do not focus on the ELF $50 \mathrm{~Hz}$ exposure, which is of course also present for the considered sources and will sometimes be mentioned. 


\section{B. Measurement equipment and procedure}

In this study, exposure levels were assessed using broadband and frequency-selective narrowband equipment. Two types of measurement probes and systems were used covering the $300 \mathrm{~Hz}$ to $10 \mathrm{MHz}$ IF range, namely the EHP 200 and EHP 50C probes (Narda Safety Test Solutions, Milan, Italy).

The IF fields between $9 \mathrm{kHz}$ up to $30 \mathrm{MHz}$ can be measured using an (isotropic) electric- and magnetic-field analyzer of type PMM EHP-200. The detection ranges are $0.6 \mathrm{~mA} / \mathrm{m}-300 \mathrm{~A} / \mathrm{m}$ for the magnetic field and $0.02-1000 \mathrm{~V} / \mathrm{m}$ for the electric field. The expanded measurement uncertainty is smaller than $23.4 \%{ }^{(4)}$.

The fields from $5 \mathrm{~Hz}$ up to $100 \mathrm{kHz}$ were measured using an electric- and magnetic-field analyzer of type PMM EHP-50C (accuracy electric field $\pm 8.8 \%$, accuracy magnetic field $\pm 6.3 \%$ ). The sensitivity is $0.01 \mathrm{~V} / \mathrm{m}$ for the electric field and $1 \mathrm{nT}$ for the magnetic field, respectively. The detection ranges are $0.01 \mathrm{~V} / \mathrm{m}-100 \mathrm{kV} / \mathrm{m}$ for the electric field and $1 \mathrm{nT}-10 \mathrm{mT}$ for the magnetic field.

The provided uncertainties of the measurement probes include contributions of linearity, anisotropy, frequency response, temperature, and relative humidity. They represent the expanded uncertainty evaluated using a confidence interval of $95 \%$. The positioning uncertainty is not included in these uncertainties. In Ref. (5), also perturbation by the environment, influence of the body, and spatial averaging are mentioned as uncertainties. Ref. (5) estimates $\pm 3 \mathrm{~dB}$ (-29$41 \%$ ) for the total measurement uncertainty for the fields. These measurement probes have a very small size and an optical fiber link. Therefore, accurate and sensitive measurements are possible and the probes are suitable for measurements near IF sources. 
The following measurement procedure was applied. First, the frequency spectrum of the magnetic and electric fields near the IF source was determined. The relevant frequency components were then identified and analyzed in more detail. Second, narrowband measurements of both electric fields $E$ and magnetic fields $H$ were executed at locations where people are (often) present. Third, measurements as a function of the distance (separation) from the IF source were performed. "Compliance distances" are defined as the distances outside which the electric and magnetic field levels of the IF source do not exceed the ICNIRP reference levels ${ }^{(7,8)}$ for general public and occupational exposure. The distances provided in this paper are given as distances between the surface of the field source and the surface of the probe. Measurement positions, measurement circumstances, and separations were also selected taking into account the actual usage of the considered devices.

Finally, we define the exposure ratio $(E R)$ as the ratio between the measured magnetic $\left(E R_{H}\right)$ or electric field $\left(E R_{E}\right)$ value due to the IF device and the corresponding ICNIRP reference level. Ratios smaller than 1 satisfy the ICNIRP reference levels. We compared exposure values and exposure ratios with the ICNIRP 2010 guidelines for the range $1 \mathrm{~Hz}-100 \mathrm{kHz}^{(8)}$ (although tables in ICNIRP 2010 show limits up to $10 \mathrm{MHz}$ ). Also ICNIRP 1998 was considered for frequencies above $100 \mathrm{kHz}^{(7)}$ (for ESU).

\section{RESULTS AND DISCUSSION}

\section{A. General overview}

Figure 1 shows the maximal measured electric fields $E$ and magnetic fields $H$ at 5 and $15 \mathrm{~cm}$ from all IF sources (over all measured sources of a type); also the measurement uncertainties are indicated. Large differences can be noticed among the different types of IF sources. For 
fluorescent lamps values up to $470 \mathrm{~V} / \mathrm{m}$ are possible at $5 \mathrm{~cm}$ and for electrosurgical units (ESU) up to $324 \mathrm{~V} / \mathrm{m}$ (mode CF4, see further). The ICNIRP ${ }^{(8)}$ reference levels are frequency dependent $(83 \mathrm{~V} / \mathrm{m}$ and $170 \mathrm{~V} / \mathrm{m}$ for the general public and occupational exposure for the considered IF frequencies of $5-15 \mathrm{kHz}$ and $38-52 \mathrm{kHz}$ in Table 1) and can be exceeded for locations near most IF sources such as energy saving bulbs, fluorescent lamps, and touchscreens (see further). For most of the IF sources considered here, the electric field is the dominating quantity. Values up to $5.0 \mathrm{~A} / \mathrm{m}$ were measured at $5 \mathrm{~cm}$ from the hearing unit. For the other sources, the magnetic fields were considerably lower. In the following sections, we discuss the exposure of the individual IF sources and the different exposure ratios.

\section{B. Touchscreen and smart board}

Figure 2 shows (a) the touchscreen (Packard Bell) and (b) the smart board with indication of the $\mathrm{x}-, \mathrm{y}-$, and $\mathrm{z}$-axes. Both devices are installed in class rooms in different schools. Near the screen, the electric field dominates and the magnetic field is negligible. Figure 3 shows the frequency spectrum of the electric field near the touchscreen $(35 \mathrm{~cm}$ from the screen) from $9 \mathrm{kHz}$ to $300 \mathrm{kHz}$. The field of the touchscreen is clearly caused by a signal at $44 \mathrm{kHz}$ (Figure 3 (a)). For the smart board frequencies of $50 \mathrm{~Hz}, 5-15 \mathrm{kHz}$ and $52 \mathrm{kHz}$ were observed (Table 1 and Figure $3(b))$.

Table 2 summarizes the electric $E$ - and magnetic $H$-field values at $44 \mathrm{kHz}$ for different positions near the touchscreen. The coordinate system (x, y, z) from Figure 2 is used. Also the exposure ratios are provided. Clearly, the electric field dominates and the highest electric field value was measured at position 16 (right bottom at $5 \mathrm{~cm}$ from the back of the screen): the field was 155.7 V/m, which is 1.9 times above the reference levels for the general public. The reference 
level for occupational exposure $(170 \mathrm{~V} / \mathrm{m})$ was not exceeded. At this position the magnetic field was $0.3 \mathrm{~A} / \mathrm{m}$ or 64 times below the reference levels for the general public. At the other positions, the reference levels provided in Table 1, were satisfied. The electric and magnetic field values decrease clearly as a function of the distance from the screen in both $\mathrm{x}$ - and $\mathrm{y}$-direction. Figure 4 shows this fast decrease of the electric field $\mathrm{E}$ as a function of the separation from the touchscreen. From about $15 \mathrm{~cm}$ from the back on $(-15.3 \mathrm{~cm} ; \mathrm{y}<0)$, the ICNIRP reference levels for the general public were not exceeded anymore (at $-5 \mathrm{~cm}, 155.7 \mathrm{~V} / \mathrm{m}$ in Table 2). At $5 \mathrm{~cm}$ from the front $(y>5 \mathrm{~cm})$, the reference levels were not exceeded.

Figure 1 also shows the maximal measured field values near the digital smart board (results of positions indicated with 1 and 2 in Figure 2(b) at $0 \mathrm{~cm}$ and $50 \mathrm{~cm}$ from the board). The highest field value was measured in the middle at the right side of the screen (position number 2): $0.93 \mathrm{~V} / \mathrm{m}(5-15 \mathrm{kHz}), 0.42 \mathrm{~V} / \mathrm{m}(52 \mathrm{kHz})$ and $0.04 \mathrm{~A} / \mathrm{m}(5-15 \mathrm{kHz})$, which is minimal 192 and 525 times below the reference levels (general public) for the electric and magnetic fields, respectively. The $50 \mathrm{~Hz}-\mathrm{ELF}$ components were $\mathrm{E}=9.2 \mathrm{~V} / \mathrm{m}$ and $\mathrm{H}=0.02 \mathrm{~A} / \mathrm{m}$ at position 2, which are respectively 533 and 6667 times below the ICNIRP reference levels.

There is no existing research about these "new" types of IF sources to the authors' knowledge. Visual Display Units (VDUs) and television sets were mentioned in Ref. (1): IF fields occur in the frequency range 15 to $25 \mathrm{kHz}$ and at other frequencies and are of the order of a few $\mathrm{A} / \mathrm{m}$ and a few $\mathrm{V} / \mathrm{m}^{(1)}$. These values are lower than for the touchscreen and similar to these of the digital smart board. 


\section{Energy saving bulbs and fluorescent lamps}

Spectral measurements of both the electric and magnetic fields were executed using the EHP-50C probe to determine the relevant frequencies radiated by the lamps. This enables to select the optimal settings of the measurement probe. Light bulbs were warmed up and stabilized, and temporal measurements were performed to verify this. The electric fields were dominant, as also mentioned in Refs. (9) and (10). The dominating frequencies were between 38 and $52 \mathrm{kHz}$ (Table 1) and also $50 \mathrm{~Hz}$ and its harmonic frequencies (100, $200 \mathrm{~Hz})$ were measured (ELF range). For the magnetic fields, 50 and $150 \mathrm{~Hz}$ were the most important frequencies. To assess all frequencies, measurements with the EHP-50C probe were performed for three frequency ranges, corresponding to frequency span settings of $500 \mathrm{~Hz}(6 \mathrm{~Hz}-500 \mathrm{~Hz}), 10 \mathrm{kHz}(120 \mathrm{~Hz}-10 \mathrm{kHz})$, and $100 \mathrm{kHz}(1.2 \mathrm{kHz}-100 \mathrm{kHz})$ (see Table 1). The maximum-hold (max-hold) setting of the probe was used (i.e., maximum values were retained during a time interval until the reading stabilizes $)^{(19)}$. In total 6 energy saving bulbs and 5 fluorescent lamps were investigated in situ. The considered separations for the measurements were $0 \mathrm{~cm}$ (contact position), $5 \mathrm{~cm}, 10,20$, and $50 \mathrm{~cm}$ from the fluorescent lamps and energy saving bulbs.

Figure 5 shows the IF electric and magnetic fields of a fluorescent lamp as a function of the separation from the fluorescent lamp. The measurement time at each distance was $30 \mathrm{~s}$. The 45 $\mathrm{kHz}$ component dominated the electric field values (span of $100 \mathrm{kHz}$, Figure 5 (b)), while the 50 $\mathrm{Hz}$ component and its harmonics dominate the magnetic field values (span of $500 \mathrm{~Hz}$, Figure 5 (a)). The IF fields decrease of course with increasing separations from the lamp. All values measured within $500 \mathrm{~Hz}$ satisfy the ICNIRP reference levels for occupational exposure, while for the span of $100 \mathrm{kHz}(1.2 \mathrm{kHz}-100 \mathrm{kHz})$ the reference levels are exceeded in Figure 5. From about $15 \mathrm{~cm}$ and $25 \mathrm{~cm}$ on, the reference levels for occupational and general public exposure 
were satisfied, respectively. The maximal electric field value near a fluorescent lamp was 1244.9 V/m or 7.2 times above the ICNIRP reference levels for occupational exposure (45 kHz). At $5 \mathrm{~cm} 471 \mathrm{~V} / \mathrm{m}(2.8$ times above ICNIRP) and at $10 \mathrm{~cm} 241 \mathrm{~V} / \mathrm{m}(1.4$ times above ICNIRP) was measured. Compliance with the basic restrictions was not investigated.

A large variation among the field levels of different lamps were noticed. Highest field levels close to energy saving bulbs were measured in a home. In the kitchen, the highest electric field value at $50 \mathrm{kHz}$ at $5 \mathrm{~cm}$ distance was $117.3 \mathrm{~V} / \mathrm{m}$ or 1.42 times above the reference level for the general public of $83 \mathrm{~V} / \mathrm{m}$ (see also Figure 1). At $15 \mathrm{~cm}$, values up to $96.6 \mathrm{~V} / \mathrm{m}$ were obtained (56.8\% of ICNIRP occupational, 1.16 times above ICNIRP general public) for $46 \mathrm{kHz}$. At $20 \mathrm{~cm}$ or further from the energy saving bulbs, the reference levels were satisfied.

These results are in line with those reported in literature. Spot measurements near compact fluorescent lights were performed in Ref. (9) and the maximal recorded electric-field strength in the $1.2-100 \mathrm{kHz}$ frequency range in close proximity of the lamps was larger than $87 \mathrm{~V} / \mathrm{m}$ for 9 of the 19 investigated lamps ${ }^{(9)}$. The highest measured value was $216 \mathrm{~V} / \mathrm{m}$ (separations of 10 and 15 $\mathrm{cm}$ were considered). This is in agreement with our results (Figure 5); our maximal value at $10 \mathrm{~cm}$ was $241 \mathrm{~V} / \mathrm{m}$ for fluorescent lamps. As mentioned above, we obtained at $15 \mathrm{~cm}$ values up to $96.6 \mathrm{~V} / \mathrm{m}$ for CFLs. In Ref. (10), $11 \mathrm{CFLs}$ have been measured in the $10 \mathrm{kHz}-1 \mathrm{MHz}$ range. Incident electric-field levels significantly exceeded the ICNIRP reference levels: e.g., up to 497\% at $15 \mathrm{~cm}$, often around $100 \%$ (Figure 7 in $\operatorname{Ref}(10)$ ) of the ICNIRP reference levels for the general public. We obtained values up to about $210 \%$ at $15 \mathrm{~cm}$ (Figure 5 (b)) for general public. Also basic restrictions were investigated in Ref. (10) and the induced fields were within the ICNIRP basic restrictions. 


\section{Portable hearing unit}

Figure 2 (c) shows the portable hearing unit and the used coordinate system. This unit helps people with hearing difficulties at ticket offices (counters) and amplifies the speech. The dimensions are $24 \mathrm{~cm} \times 5 \mathrm{~cm} \times 17 \mathrm{~cm}$. First, a spectral measurement near the hearing unit revealed its relevant IF frequencies. The measurements were performed with the EHP-50C probe with a span of $200 \mathrm{~Hz}$ (ELF frequencies) and $10 \mathrm{kHz}$ (IF frequencies); in this way a frequency range of $5 \mathrm{~Hz}$ to $10 \mathrm{kHz}$ was obtained. The hearing unit was installed in a room with a constant background noise, as it is used in operating conditions. Broadband IF frequency components up to $5 \mathrm{kHz}$ were measured (see Figure 3 for constant sound noise; $6 \mathrm{kHz}$ for an interfering sound signal), while for the ELF frequencies, $50 \mathrm{~Hz}$ and its harmonics $(150 \mathrm{~Hz})$ were measured. The setting of the measurement probe was wideband and the max-hold mode ${ }^{(19)}$. The measurement time per position was $30 \mathrm{~s}$ which is the time needed for the signal of the hearing unit to stabilize. Ten different modes of the hearing unit have been evaluated; these modes are used in practice. Measurements occurred at a fixed position for the following different configurations of the hearing unit:

a) Unit swithed off.

b) Unit works on batteries without using an external adapter, loud speaker, microphone or headset.

c) Unit works with 220 Volt net adaptor (electric mains) without connection of external microphone. The headset is also not connected.

d) Unit works with 220 Volt net adaptor (electric mains) with connection of external microphone. The headset is not connected.

e) Unit works with batteries with connection of an external microphone. The headset is not connected.

f) Unit works with 220 Volt net adaptor with connection of external loud speaker. The headset is not connected.

g) Unit works with 220 Volt net adaptor with connection of external microphone and the headset.

Measurements that occurred as a function of the type of noise at a fixed position:

h) No noise. 
i) In environment with continuous background noise.

j) Measurement with an interfering signal caused by an external microphone and headset (placing them close to each other).

Next, measurements as a function of distance to the unit from different sides were performed for various modes.

\section{1) Influence of different configurations}

Table 3 summarizes the field values for various configurations of the hearing unit. The measurements were performed at the front side of the unit at the contact position. Both for the $200 \mathrm{~Hz}$ and $10 \mathrm{kHz}$ span, the background radiation in the environment was measured (mode a) and these values were similar as when the unit works on batteries (mode b). When connected to the electric mains $(220 \mathrm{~V})$, the values were considerably higher for modes b-c-f-g (for IF $10 \mathrm{kHz}$ : order $60-70 \mathrm{~V} / \mathrm{m}$ versus $2 \mathrm{~V} / \mathrm{m}, 10 \mathrm{~A} / \mathrm{m}$ versus $0.2 \mathrm{~A} / \mathrm{m}$ ). Without connection to the electric mains, the magnetic fields were similar to mode a (when switched off), mainly the $50 \mathrm{~Hz}$ component of the background was measured. When the unit is connected to the electric mains and switched on, the broadband IF signal up to $5 \mathrm{kHz}$ of Figure 3 (c) was measured next to the $50 \mathrm{~Hz}$ signal.

All values in Table 3 satisfy the ICNIRP reference levels for occupational exposure and for the general public: the highest value for the $10 \mathrm{kHz}$ span was $69 \mathrm{~V} / \mathrm{m}$ and $10.5 \mathrm{~A} / \mathrm{m}$ or 2.4 and 8 times below ICNIRP for occupational exposure, respectively (up to $83 \%$ of ICNIRP for the general public). For the $200 \mathrm{~Hz}$ span (due to $50 \mathrm{~Hz}$ component and harmonics), $414 \mathrm{~V} / \mathrm{m}$ and $2.0 \mathrm{~A} / \mathrm{m}$ was measured, 6 and 396 times below ICNIRP for occupational exposure, respectively. The IF frequencies are dominant for the hearing unit. 


\section{2) Influence of the type of noise or sound signal}

In this section, the influence of the type of sound signal on the resulting electric and magnetic fields is investigated. The modes $\mathrm{h}-\mathrm{i}-\mathrm{j}$ (silent, constant noise sound, interference sound) of Section III.D were investigated in the contact position in the front of the hearing unit, which was connected to the electricity mains. The setting was wideband and max-hold with a span of $10 \mathrm{kHz}$ (IF signals). These measurements were performed during 5 minutes, which is the time for the IF signal caused by the hearing unit to stabilize. Figure 3 (c) shows the frequency spectrum for the different sound signal modes (noise), resulting in a different IF frequency spectrum: for constant noise an IF broadband spectrum up to $5 \mathrm{kHz}$ and a single peak at $6 \mathrm{kHz}$ for the interfering signal. The magnetic fields depend upon the type of sound signal with highest values of $10.5 \mathrm{~A} / \mathrm{m}$ for the constant background noise (mode $\mathrm{h}$, broadband up to $5 \mathrm{kHz}$ ) and $9.3 \mathrm{~A} / \mathrm{m}$ for the interference noise signal (mode j, here dominant component around $6 \mathrm{kHz}$ ). This is about 2 and 8 times below the ICNIRP reference levels for general public and occupational exposure, respectively. Without sound signal or noise (mode h), the magnetic field was only $1.3 \mathrm{~A} / \mathrm{m}$. The electric field was constant and not influenced by the sound signal (the values of Table 3 apply). As the sound causes currents to flow within the equipment, only the magnetic fields change.

3) Measurements as a function of the distance to the hearing unit

Highest field values were measured at the front and back of the portable hearing unit and therefore, measurements as a function of the separation are performed at these sides. Each measurement was performed during $30 \mathrm{~s}$, with the hearing unit connected to the electricity mains and with microphone and loudspeaker connected (causing the highest electric and magnetic field values, see Section III.D.1) and Table 3). Also a constant noise sound signal was present, causing the highest magnetic fields (Section III.D.2)). Figs. 6 (a) and (b) show the electric and magnetic 
field as a function of the separation (coordinate system of Figure 2). All field values satisfy the ICNIRP reference levels (both for ELF and IF). The fields decrease of course with increasing separations and their course is symmetrical at both sides in Figure 6, where also the hearing unit is indicated. The highest electric field value was $399 \mathrm{~V} / \mathrm{m}$ for the $200 \mathrm{~Hz}$ span and $12.64 \mathrm{~A} / \mathrm{m}$ for the span of $10 \mathrm{kHz}$.

To the authors' knowledge, IF exposure from the portable hearing units has not been considered before. Exposure from loops, such as in EAS systems ${ }^{(3,4,6)}$ and also integrated in the hearing unit has been investigated.

\section{E. Electrosurgical unit}

An electrosurgical unit (ESU) type Valleylab Force FX was investigated in a hospital environment. Separations of $0.5,5$, and $20 \mathrm{~cm}$ were considered. As mentioned in Ref. (15), such units are used for chirurgical operations and radiate in the IF frequency band. Measurements were performed with the EHP-200A spectral measurement equipment. The ESU has different operational modes (blend $200 \mathrm{~W}$, coagulation fulguration $120 \mathrm{~W}$, blend cut $200 \mathrm{~W}$, coagulation desication $120 \mathrm{~W}$, coagulation spray $120 \mathrm{~W}$, pure cut $300 \mathrm{~W}$ ) and for each of the modes measurements were performed. A summary of the different modes and the measurements is provided in Tables 4 and 5. Also maximal voltages (up to 9000 volt peak-to-peak), powers (up to $300 \mathrm{~W}$ ), and corresponding duty cycles are listed in Table 4. The duty cycles of the ESU were determined from the crest factors provided by the manufacturer. All measurements occurred in a box of water where the ESU was used to cut in the various modes (Table 4). As stated in Ref. (15), the applied voltage and current will vary compared to "live" materials because of the variations in resistance of the different materials being cut in reality. The measurements here were performed in a worst-case situation at various positions near the feeding cable. Table 5 lists 
also the different measurement setups and positions for the various modes. These modes and positions were selected because these were the modes used in practice by the medical personnel. In total 24 measurements are described in Table 5.

The setting of the EHP-200A probe was wideband and max-hold with a span of $940 \mathrm{kHz}$, $400 \mathrm{kHz}, 2 \mathrm{MHz}$, and $30 \mathrm{MHz}$. Frequencies up to $940 \mathrm{kHz}$ were identified (Table 1). Electric and magnetic fields at similar frequencies were generated and both were important ${ }^{(16)}$. For the comparison with the ICNIRP guidelines, we compare the total signal in the band with the most strict norm in the band, which is a worst-case approach. Table 5 lists the measured electric- and magnetic-field values and the calculated duty cycles. In this table, the root-mean-square (RMS) electric and magnetic fields are compared with both the ICNIRP $1998^{(7)}$ (frequencies above $100 \mathrm{kHz}$ ) and $2010^{(8)}$ reference levels. For comparison with ICNIRP 1998, we compared with the most strict limit in the considered frequency band and made thus a worst-case estimation. We compare in this table with the guidelines for occupational exposure. We applied a (realistic) worst-case approach: the values are provided for a $100 \%$ duty cycle and for the actual maximal duty cycles of Table 4 . Thus, both the maximal fields $E$ and $H$ (assuming continuous working mode, which is an overestimation) and the fields accounting for the maximal duty cycles $E_{\text {dcycle }}$ and $H_{d c y c l e}$ are listed in the Table 5. Previous studies ${ }^{(15,16)}$ reported that during operations (lasting 3-4 hours), the ESU was activated about half an hour in total. So applying the maximal duty cycle of an operating mode for estimations of 6-minutes can be considered as "realistic" worst-case. The ICNIRP 1998 reference levels ${ }^{(7)}$ were exceeded at various positions for both electric and magnetic fields (indicated in bold in Table 5), up to 1.7-2 times for 100\% duty cycles and 1-1.3 times for actual duty cycles. Also the ICNIRP 2010 reference levels ${ }^{(8)}$ were exceeded up to 7 times for the electric field near the ESU. The ICNIRP guidelines were not exceeded for the 
positions (CF7 and CF12) with separations of $20 \mathrm{~cm}$. The highest maximal electric-field value was $1203.5 \mathrm{~V} / \mathrm{m}$ for measurement CF2 using the fulguration mode with $120 \mathrm{~W}$ and $1118.3 \mathrm{~V} / \mathrm{m}$ for measurement CP1 using the pure cut mode with $300 \mathrm{~W}$ (no duty cycle into account thus $100 \%$ of time, $\mathrm{H}$ is $1.1 \mathrm{~A} / \mathrm{m}$ for $\mathrm{CF} 2$ and $2.7 \mathrm{~A} / \mathrm{m}$ for $\mathrm{CP} 2$ ). This measurement was performed at $0.5 \mathrm{~cm}$ from the feeding cable. The highest magnetic field value (100\% duty cycle) was $2.7 \mathrm{~A} / \mathrm{m}$ for the pure cut (measurement PC2) at $0.5 \mathrm{~cm}$ from the unit. When applying duty cycles (comparison with ICNIRP 1998) these values reduce to $792 \mathrm{~V} / \mathrm{m}$ and $1.8 \mathrm{~A} / \mathrm{m}$.

In the literature ${ }^{(15,16,17)}$, also values exceeding the reference levels were measured and it was also mentioned that the fields vary considerably among the different modes. In Ref. (15), the calculated magnetic field exceeded at $10 \mathrm{~cm}$ the ICNIRP 1998 guidelines for some modes: maximally $0.82 \mathrm{kV} / \mathrm{m}$ was obtained. In Ref. (17), fields at $16 \mathrm{~cm}$ varied from 120 to $1000 \mathrm{~V} / \mathrm{m}$ and 0.06 to $0.71 \mathrm{~A} / \mathrm{m}$ depending on the mode of operation with frequencies of approximately 10 to $30 \mathrm{kHz}^{(17)}$. These values are comparable with ours of $0.8 \mathrm{kV} / \mathrm{m}$ and $1.8 \mathrm{~A} / \mathrm{m}$ (pure cut operation, duty cycle of 44\%). In Ref. (16), electric fields were measured at distances from 5$30 \mathrm{~cm}$ from the lead wire and calculations provided estimates of even up to $15 \mathrm{kV} / \mathrm{m}(16 \mu \mathrm{T}$ or $12.7 \mathrm{~A} / \mathrm{m}$ ) at the surgeon's hand, exceeding the reference levels. Among the exposure sources investigated in Ref. (6), also medical devices for surgery were investigated and for cutting, values of $553 \mathrm{~V} / \mathrm{m}(10 \mathrm{~cm}$ from ESU) and $248 \mathrm{~V} / \mathrm{m}$ at $0.5 \mathrm{~cm}$ from the source during a simulated operation were obtained. We obtained also the highest fields for the pure cutting mode.

\section{CONCLUSIONS}

Spectral in-situ exposure assessment of both the electric and magnetic fields of different intermediate frequency sources (smart boards and large touchscreens, energy saving light bulbs, 
fluorescent lamps, portable hearing units and electrosurgical units) was investigated in this paper. For most of these sources the electric field is the dominating quantity. ICNIRP reference levels were exceeded for touchscreens, fluorescent lamps, and electrosurgical units. Large differences of measured field values exist among the various operating modes of the IF equipment. Therefore, different working modes have been considered for the exposure assessment. Compliance with the general public reference levels can be obtained by increasing the separation from the device: compliance distances of $15 \mathrm{~cm}$ (touchscreen), $20 \mathrm{~cm}$ (energy saving bulbs), and $25 \mathrm{~cm}$ (fluorescent lamps were obtained. The reference levels were not exceeded for the portable hearing unit ( $83 \%$ of ICNIRP). At positions $20 \mathrm{~cm}$ from the electrosurgical unit, (occupational) reference levels were satisfied for the investigated configurations and ESU.

Further research is needed to quantify in-situ IF radiation as there is only limited literature available. Moreover, simulations or measurements of induced electric fields, current density, and specific absorption rate (SAR) to investigate compliance with the basic restrictions is highly relevant and should be part of future research.

\section{REFERENCES}

1. Litvak, E., Foster, K., Repacholi, M. Health and safety implications of exposure to electromagnetic fields in the frequency range $300 \mathrm{~Hz}$ to $10 \mathrm{MHz}$. Bioelectromagnetics 23(1), 68-82 (2002).

2. World Health Organization (WHO). Electromagnetic fields and public health - intermediate frequencies (IF) Information sheet 2005, available at: http://www.who.int/pehemf/publications/facts/intermediatefrequencies_infosheet.pdf and http://www.who.int/pehemf/publications/facts/intmedfrequencies/en/, Last Accessed November 25, 2013 
3. Trulsson, J., Anger, G., and Estenberg, U. Assessment of Magnetic Fields Surrounding Electronic Article Surveillance Systems in Sweden. Bioelectromagnetics 28, 664-666 (2007).

4. Joseph, W., Vermeeren, G., Verloock, L., Goeminne, F. "In-situ magnetic field exposure and ICNIRP based safety distances for electronic article surveillance systems". Radiation protection dosimetry 148(4), 420-427 (2012).।

5. CENELEC European Committee for Electrotechnical Standardisation. Basic standard for the in-situ measurement of electromagnetic field strength related to human exposure in the vicinity of base stations. TC 106x WG1 EN 50492 in situ. (Brussels, Belgium: European Committee for Electrotechnical Standardization) (2008).

6. Floderus, B., Stenlund, C., Carlgren, F. Occupational exposures to high frequency electromagnetic fields in the intermediate range ( $>300 \mathrm{~Hz}-10 \mathrm{MHz}$ ), Bioelectromagnetics 23(8), 568-77 (2002).

7. International Commission on Non-ionizing Radiation Protection (ICNIRP). Guidelines for limiting exposure to time-varying electric, magnetic, and electromagnetic fields (up to 300 GHz). Health Phys 74(4), 494-522 (1998).

8. International Commission on Non-Ionizing Radiation Protection (ICNIRP). Guidelines for limiting exposure to time- varying electric and magnetic fields (1 Hz to $100 \mathrm{kHz})$. Health Phys 99(6), 818-836 (2010).

9. Bakos, J., Nagy, N., Juhász, P., Thuróczy, G. Spot measurements of intermediate frequency electric fields in the vicinity of compact fluorescent lamps. Radiation Protection Dosimetry 142(2-4), 354-357 (2010). 
10. Nadakuduti, J., Douglas, M., Capstick, M., Kuhn, S., Kuster, N. Application of an Induced Field Sensor for Assessment of Electromagnetic Exposure From Compact Fluorescent Lamps, Bioelectromagnetics 33, 166-175 (2012)

11. Christ, A., Guldimann, R., Bühlmann, B., Zefferer, M., Bakker, J.F., van Rhoon, G.C., Kuster, N. Exposure of the Human Body to Professional and Domestic Induction Cooktops Compared to the Basic Restrictions. Bioelectromagnetics 33(8), 695-705 (2012).

12. Kos, B., Valič, B., Miklavčič, D., Kotnik, T., Gajšek, P. Pre-and post-natal exposure of children to EMF generated by domestic induction cookers. Phys Med Biol 56(19), 6149-6160 (2011).

13. Joseph, W., Goeminne, F., Verloock, L., Vermeeren, G., Martens, L. In-situ Occupational and General Public Exposure to Non-directional Beacons for Air Traffic Control, Bioelectromagnetics 3(3), 274-277, (2012).

14 Joseph, W., Goeminne, F., Verloock, L., Vermeeren, G., Martens, L. Occupational and public field exposure from communication, navigation, and radar systems used for air traffic control. Health Physics 103(6), 750-762, (2012).

15. Wilen J. Exposure Assessment of Electromagnetic Fields Near Electrosurgical Units. Bioelectromagnetics 31, 513-518 (2010).

16. Liljestrand, B., Sandstrom, M., Hansson, M. K. RF exposure during use of electrosurgical units. Electromagn Biol Med 22, 127-132 (2003).

17. Mantiply, E., Pohl, K., Poppell, S., Murphy, J. Summary of measured radiofrequency electric and magnetic fields (10 kHz to $30 \mathrm{GHz})$ in the general and work environment. Bioelectromagnetics 18, 563-577 (1997).

18. Aerts, S, Verloock, L., Martens, L., Joseph, W. Compliance boundaries for train protection systems. Radiation protection dosimetry (2013) [Epub ahead of print]. 
19. Joseph, W., Olivier, C., Martens, L. A Robust, Fast and Accurate Deconvolution Algorithm for EM-field Measurements around GSM and UMTS base stations with a spectrum analyzer. IEEE Trans. Instr. Meas. 51(6), 1163 - 1169 (2002). 


\section{Author affiliations}

Matthias Van Den Bossche *, Leen, Verloock *, Sam Aerts *, Wout, Joseph *, and Luc, Martens * *Department of Information Technology, Ghent University / iMinds,

Gaston Crommenlaan 8, box 201, B-9050 Ghent, Belgium, fax: +32 93314899

(email:wout.joseph@intec.UGent.be)

Acknowledgement: This work was financially supported by the INTERREG IV project WiSE. 


\section{List of captions}

Table 1: Investigated IF sources, the corresponding identified frequencies and ICNIRP reference levels for the general public and occupational exposure for the electric and magnetic fields.

Table 2: Electric- and magnetic-field values measured near the touchscreen and the corresponding exposure ratios (ratios exceeding the reference levels are indicated in bold).

Table 3: Summary of the electric- and magnetic-field values for various modes of the hearing unit and comparison with the ICNIRP reference levels (occupational and general public).

Table 4: Different modes and configuration of investigated ESU, maximal voltages and powers, and corresponding duty cycles.

Table 5: Electric and magnetic fields due to ESU for the different configurations and modes and comparison with the ICNIRP 1998 reference levels (ratios exceeding the reference levels are indicated in bold).

Figure 1: Maximal (a) electric and (b) magnetic fields at 5 and $15 \mathrm{~cm}$ from the considered IF sources.

Figure 2: Pictures of (a) the touchscreen, (b) digital smart board, and (c) portable hearing unit with indication of $x-, y$-, and z-axis.

Figure 3: Frequency spectrum of the electric field (a) of the touchscreen for frequencies from $9 \mathrm{kHz}$ to $300 \mathrm{kHz}$, (b) of the smart board for frequencies from $5 \mathrm{~Hz}$ to $100 \mathrm{kHz}$, and (c) of the magnetic field of the portable hearing unit for frequencies from $5 \mathrm{~Hz}$ to $100 \mathrm{kHz}$ and for different sound noise modes (silent, constant noise sound, interference sound). 
Figure 4: Electric field of the touchscreen measured along y-axis (front and back of the touchscreen) as a function of distance ( $x=0 \mathrm{~cm}$ and $\mathrm{z}=21.5 \mathrm{~cm}$, see Figure 2); the touchscreen is positioned at $y=0 \mathrm{~cm}$.

Figure 5: Electric- and magnetic-field values of the fluorescent lamp as a function of the separation measured with (a) span of $500 \mathrm{~Hz}(6 \mathrm{~Hz}-500 \mathrm{~Hz})$, (b) span of $100 \mathrm{kHz}(1.2-100 \mathrm{kHz})$, and indication of the ICNIRP reference levels for occupational exposure.

Figure 6: (a) Electric- and (b) magnetic-field values of the portable hearing unit as a function of the separation for the $200 \mathrm{~Hz}$ and $10 \mathrm{kHz}$ span, with indication of the ICNIRP reference levels. 


\begin{tabular}{|c|c|c|c|c|c|c|c|}
\hline \multirow[t]{2}{*}{ IF source } & \multirow[t]{2}{*}{ location } & \multirow[t]{2}{*}{$\begin{array}{l}\text { frequency } \\
(\mathrm{kHz})\end{array}$} & \multicolumn{2}{|c|}{$\begin{array}{l}\text { reference level } \\
\text { ICNIRP } 2010 \\
\text { (general public) }\end{array}$} & \multicolumn{2}{|c|}{$\begin{array}{l}\text { reference level } \\
\text { ICNIRP 2010 } \\
\text { (occupational) }\end{array}$} & \multirow[t]{2}{*}{ \#meas } \\
\hline & & & $\mathrm{E}(\mathrm{V} / \mathrm{m})$ & $\mathrm{H}(\mathrm{A} / \mathrm{m})$ & $\mathrm{E}(\mathrm{V} / \mathrm{m})$ & $\mathrm{H}(\mathrm{A} / \mathrm{m})$ & \\
\hline \multirow[t]{2}{*}{ touchscreen } & school & 0.05 & 5000 & 100 & 10,000 & 800 & 34 \\
\hline & & 44 & 83 & 21 & 170 & 80 & \\
\hline \multirow[t]{3}{*}{ Smart board } & school & 0.05 & 5000 & 100 & 10,000 & 800 & 12 \\
\hline & & $5-15$ & 83 & 21 & 170 & 80 & \\
\hline & & 52 & 83 & 21 & 170 & 80 & \\
\hline energy saving & school, homes & 0.05 & 5000 & 100 & 10,000 & 800 & 46 \\
\hline bulbs, light & & 0.10 & 2500 & 160 & 5000 & 800 & \\
\hline \multirow[t]{2}{*}{ bulbs } & & 38 & 83 & 21 & 170 & 80 & \\
\hline & & $43-44$ & 83 & 21 & 170 & 80 & \\
\hline fluorescent & schools, homes & $0.05-0.015$ & 5000 & $1280-267$ & 20,000 & $6520-1333$ & 26 \\
\hline \multirow[t]{2}{*}{ lamps } & & 0.05 & 5000 & 100 & 10,000 & 800 & \\
\hline & & $45 ; 52$ & 83 & 21 & 170 & 80 & \\
\hline \multirow{3}{*}{$\begin{array}{l}\text { Electrosurgical } \\
\text { unit ESU } 1998 \\
\text { ESU } 2010\end{array}$} & hospital & $0 / 940$ & $87^{*}$ & $0.8^{*}$ & $610^{*}$ & $1.7^{*}$ & 24 \\
\hline & & $190 / 590$ & $87 *$ & $1.2^{*}$ & $610^{*}$ & $2.7 *$ & \\
\hline & & $0 / 940 / 190 / 590$ & 83 & 21 & 170 & 80 & \\
\hline \multirow{2}{*}{$\begin{array}{l}\text { Portable hearing } \\
\text { unit }\end{array}$} & ticket office, & 0.200 & 1250 & 160 & 2500 & 800 & 59 \\
\hline & counter & $5 / 10$ & 83 & 21 & 170 & 80 & \\
\hline
\end{tabular}

\#meas = number of measurements

*for ESU: ICNIRP 1998 guidelines

Table 1 


\begin{tabular}{lcccccccc}
\hline position & no. & $\begin{array}{c}\mathrm{x} \\
(\mathrm{cm})\end{array}$ & $\begin{array}{c}\mathrm{y} \\
(\mathrm{cm})\end{array}$ & $\begin{array}{c}\mathrm{z} \\
(\mathrm{cm})\end{array}$ & $\begin{array}{c}\mathrm{E} \\
(\mathrm{V} / \mathrm{m})\end{array}$ & $\begin{array}{c}\mathrm{H} \\
(\mathrm{A} / \mathrm{m})\end{array}$ & $\begin{array}{c}\mathrm{ER}_{\mathrm{E}} \\
(-)\end{array}$ & $\begin{array}{c}\mathrm{ER}_{\mathrm{H}} \\
(-)\end{array}$ \\
\hline In front of screen, right. & 1 & 0 & 5 & 21.5 & 33.34 & 0.11 & 0.50 & 0.01 \\
& 2 & 0 & 10 & 21.5 & 20.42 & - & 0.25 & - \\
& 3 & 0 & 20 & 21.5 & 4.17 & - & 0.05 & - \\
& 4 & 0 & 50 & 21.5 & 1.69 & - & 0.02 & - \\
& 5 & 0 & 100 & 21.5 & 0.24 & - & 0.00 & - \\
\hline In front of screen, right & 6 & 0 & 5 & 0 & 5.07 & - & 0.06 & - \\
below. & & & & & & & & \\
& & & & & & & \\
In front of screen, right & 7 & 0 & 5 & & & & \\
top. & 8 & -60 & 0 & 21.5 & 0.51 & - & - & - \\
\hline In front of screen, left & 9 & -30 & 0 & 21.5 & 1.90 & - & 0.02 & - \\
\hline In front of screen, & 10 & -30 & 35 & 5 & 0.71 & - & 0.01 & - \\
middle & 11 & 5 & 0 & 21.5 & 59.84 & 0.19 & 1.00 & 0.01 \\
\hline side of screen, right & 12 & 10 & 0 & 21.5 & 28.40 & - & 0.33 & - \\
& 13 & 20 & 0 & 21.5 & 21.54 & - & 0.25 & - \\
& 14 & 50 & 0 & 21.5 & 5.29 & - & 0.06 & - \\
& 15 & 100 & 0 & 21.5 & 1.04 & - & 0.01 & - \\
\hline back of screen, right & 16 & 0 & -5 & 21.5 & 155.66 & 0.33 & $\mathbf{1 . 9 0}$ & 0.02 \\
& 17 & 0 & -20 & 21.5 & 49.73 & - & 0.50 & - \\
\hline
\end{tabular}

'-‘: below sensitivity of measurement probe $(<0.05 \mathrm{~A} / \mathrm{m})$.

Table 2 



\begin{tabular}{|c|c|c|c|c|c|c|c|c|c|c|c|c|}
\hline \multirow[b]{2}{*}{ configuration } & \multirow[b]{2}{*}{$\begin{array}{c}\mathrm{E} \\
(\mathrm{V} / \mathrm{m}) \\
\end{array}$} & \multirow[b]{2}{*}{$\begin{array}{c}\mathrm{H} \\
(\mathrm{A} / \mathrm{m})\end{array}$} & \multicolumn{2}{|c|}{$\begin{array}{l}\text { span } 200 \mathrm{~Hz} \\
\text { occupational }\end{array}$} & \multicolumn{2}{|c|}{ general public } & \multirow[b]{2}{*}{$\begin{array}{c}\mathrm{E} \\
(\mathrm{V} / \mathrm{m})\end{array}$} & \multirow[b]{2}{*}{$\begin{array}{c}\mathrm{H} \\
(\mathrm{A} / \mathrm{m}) \\
\end{array}$} & \multicolumn{2}{|c|}{$\begin{array}{l}\text { span } 10 \mathrm{kHz} \\
\text { occupational }\end{array}$} & \multicolumn{2}{|c|}{ general public } \\
\hline & & & $\begin{array}{c}E R_{E} \\
(-)\end{array}$ & $\begin{array}{c}E R_{H} \\
(-) \\
\end{array}$ & $\begin{array}{c}E R_{E} \\
(-)\end{array}$ & $\begin{array}{c}E R_{H} \\
(-)\end{array}$ & & & $\begin{array}{c}E R_{E} \\
(-)\end{array}$ & $\begin{array}{c}E R_{H} \\
(-) \\
\end{array}$ & $\begin{array}{c}E R_{E} \\
(-)\end{array}$ & $\begin{array}{c}E R_{H} \\
(-)\end{array}$ \\
\hline Unit off (a) & 15 & 0.24 & 0.01 & 0.00 & 0.01 & 0.002 & 2 & 0.3 & 0.01 & 0.002 & 0.03 & 0.01 \\
\hline Unit on with batteries (b) & 15 & 0.23 & 0.01 & 0.00 & 0.01 & 0.002 & 2 & 0.34 & 0.01 & 0.004 & 0.03 & 0.01 \\
\hline $\begin{array}{l}\text { Unit on with electric mains } \\
\text { (c) }\end{array}$ & 414 & 0.31 & 0.17 & 0.00 & 0.33 & 0.003 & 69 & 0.32 & 0.50 & 0.003 & 0.83 & 0.01 \\
\hline $\begin{array}{l}\text { Unit on with electric mains } \\
+ \text { micro (d) }\end{array}$ & 399 & 1.60 & 0.17 & 0.002 & 0.33 & 0.02 & 66 & 10.44 & 0.33 & 0.13 & 0.77 & 0.50 \\
\hline $\begin{array}{l}\text { Unit on with batteries + } \\
\text { micro (e) }\end{array}$ & 4 & 1.68 & 0.00 & 0.00 & 0.00 & 0.02 & 6 & 9.87 & 0.04 & 0.12 & 0.08 & 0.50 \\
\hline $\begin{array}{l}\text { Unit on with electric mains } \\
+ \text { headset (f) }\end{array}$ & 381 & 0.23 & 0.14 & 0.00 & 0.33 & 0.002 & 65 & 0.39 & 0.33 & 0.004 & 0.76 & 0.02 \\
\hline $\begin{array}{l}\text { Unit on with electric mains } \\
+ \text { micro }+ \text { loudspeaker }(\mathrm{g})\end{array}$ & 377 & 2.02 & 0.14 & 0.02 & 0.33 & 0.02 & 64 & 10.45 & 0.33 & 0.13 & 0.77 & 0.50 \\
\hline
\end{tabular}

Table 3 


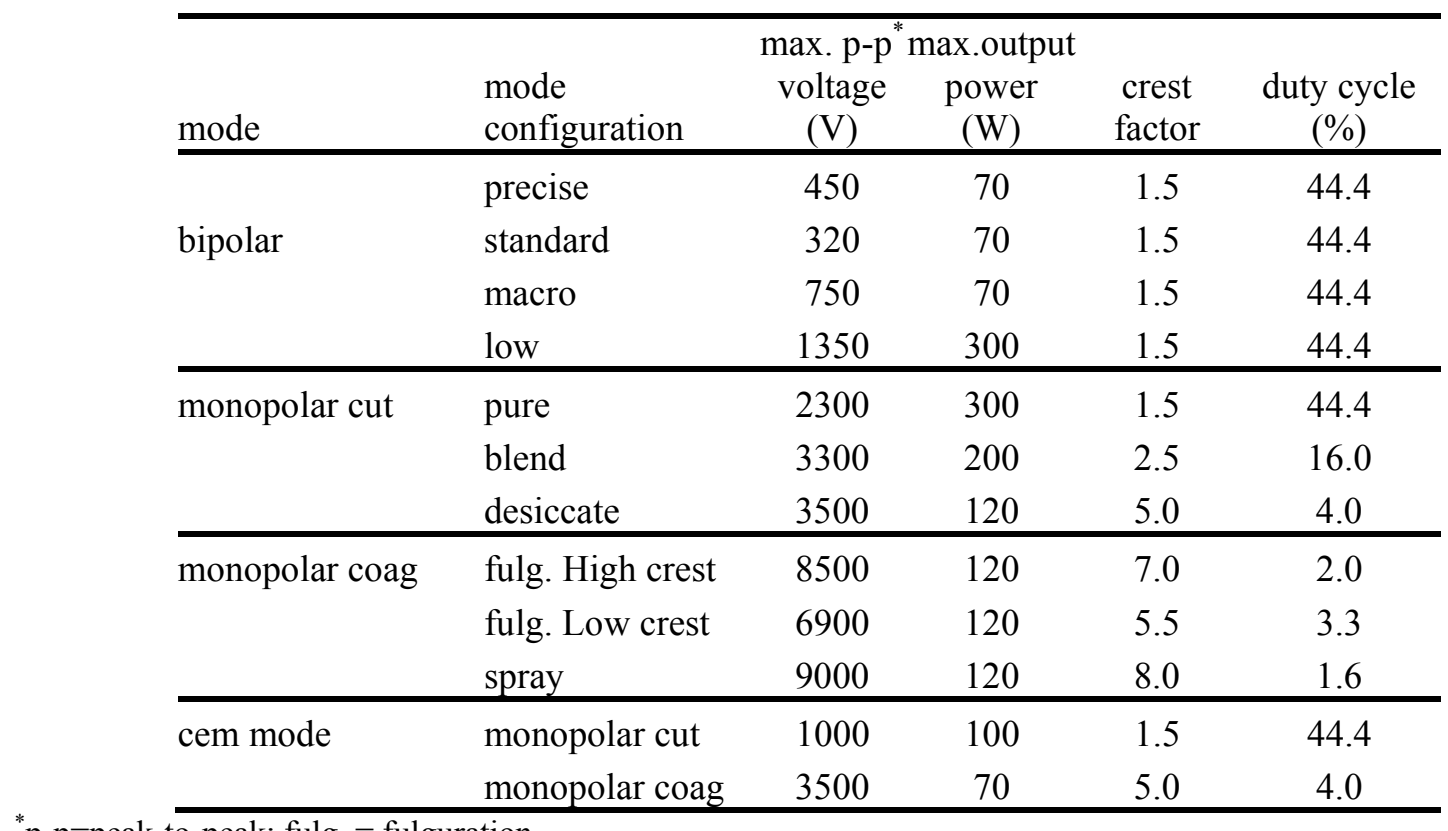

"p-p=peak-to-peak; fulg. = fulguration

Table 4 



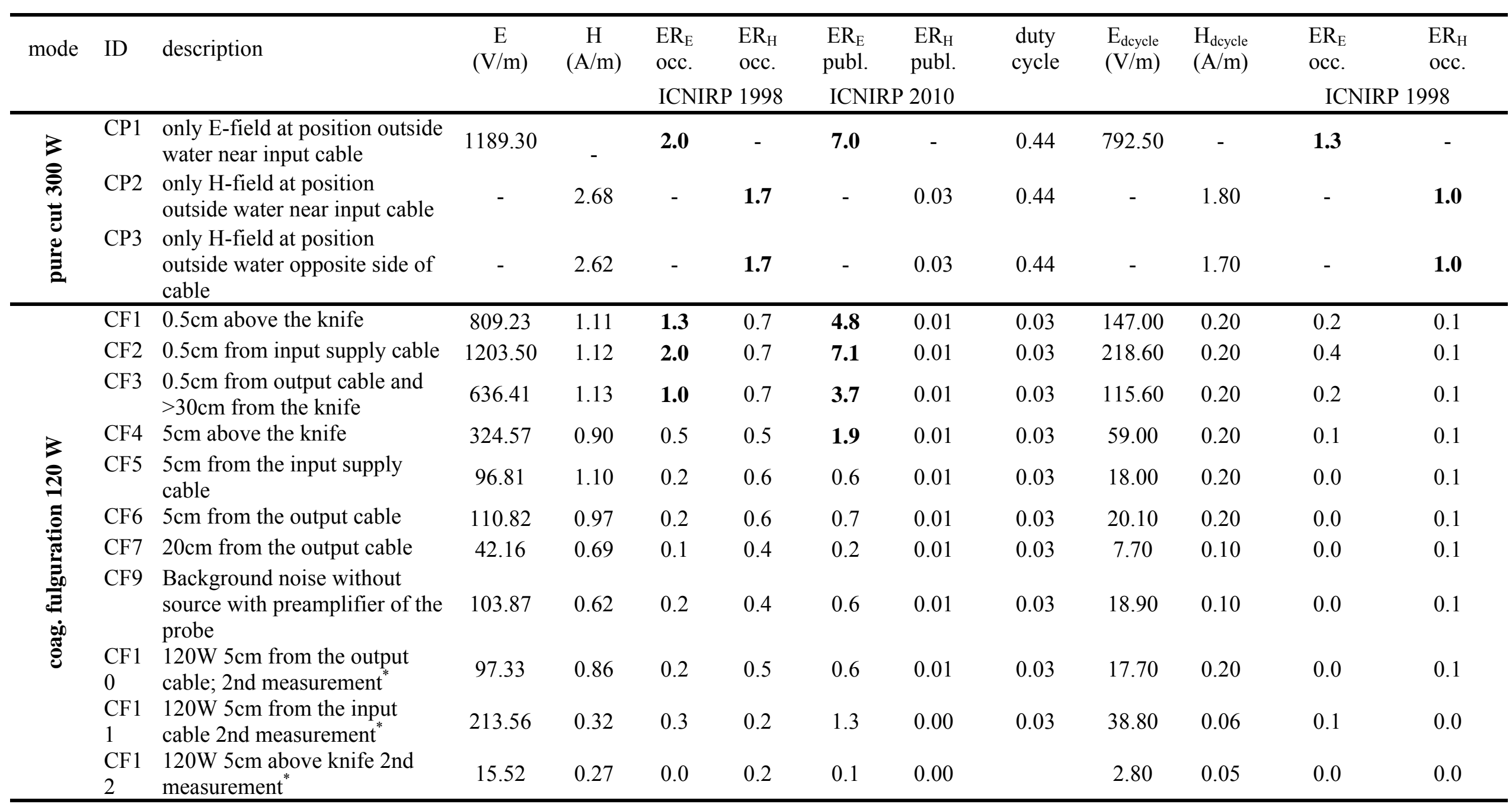




\begin{tabular}{|c|c|c|c|c|c|c|c|c|c|c|c|c|c|}
\hline \multirow{3}{*}{ 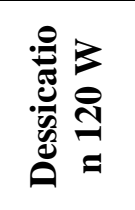 } & CD1 & $0.5 \mathrm{~cm}$ from the output cable & 195.51 & 1.40 & 0.3 & 0.8 & 1.2 & 0.02 & 0.04 & 39.10 & 0.28 & 0.1 & 0.2 \\
\hline & $\mathrm{CD} 2$ & $\begin{array}{l}0.5 \mathrm{~cm} \text { from the input supply } \\
\text { cable }\end{array}$ & 258.03 & 1.53 & 0.4 & 0.9 & 1.5 & 0.02 & 0.04 & 51.61 & 0.31 & 0.1 & 0.2 \\
\hline & CD3 & $0.5 \mathrm{~cm}$ above the knife & 229.74 & 0.64 & 0.4 & 0.4 & 1.4 & 0.01 & 0.04 & 45.95 & 0.13 & 0.1 & 0.1 \\
\hline \multirow{3}{*}{ 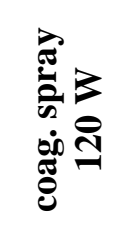 } & CS1 & $0.5 \mathrm{~cm}$ above the knife & 904.81 & 0.30 & 1.4 & 0.2 & 5.3 & 0.00 & 0.02 & 114.45 & 0.04 & 0.2 & 0.0 \\
\hline & $\mathrm{CS} 2$ & $\begin{array}{l}0.5 \mathrm{~cm} \text { from the input supply } \\
\text { cable }\end{array}$ & 243.87 & 1.28 & 0.4 & 0.8 & 1.4 & 0.02 & 0.02 & 30.85 & 0.16 & 0.1 & 0.1 \\
\hline & $\mathrm{CS} 3$ & $\begin{array}{l}0.5 \mathrm{~cm} \text { from the input supply } \\
\text { cable }\end{array}$ & 175.40 & 1.24 & 0.3 & 0.7 & 1.0 & 0.02 & 0.02 & 22.19 & 0.16 & 0.0 & 0.1 \\
\hline \multirow{3}{*}{ 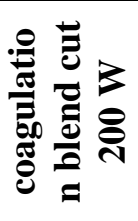 } & CB1 & $\begin{array}{l}0.5 \mathrm{~cm} \text { from the input supply } \\
\text { cable }\end{array}$ & 314.64 & 1.87 & 0.5 & 1.1 & 1.9 & 0.02 & 0.16 & 125.86 & 0.75 & 0.2 & 0.4 \\
\hline & $\mathrm{CB} 2$ & $0.5 \mathrm{~cm}$ above the knife & 213.89 & 0.55 & 0.3 & 0.3 & 1.3 & 0.01 & 0.16 & 85.56 & 0.22 & 0.1 & 0.1 \\
\hline & CB3 & $0.5 \mathrm{~cm}$ from the output cable & 273.28 & 1.93 & 0.5 & 1.1 & 1.6 & 0.02 & 0.16 & 109.31 & 0.77 & 0.2 & 0.5 \\
\hline
\end{tabular}

ID = measurement ID; occ = occupational; publ. = general public; dcycle = duty cycle; coag. = coagulation *second measurement validation measurement to check reproducibility

Table 5 


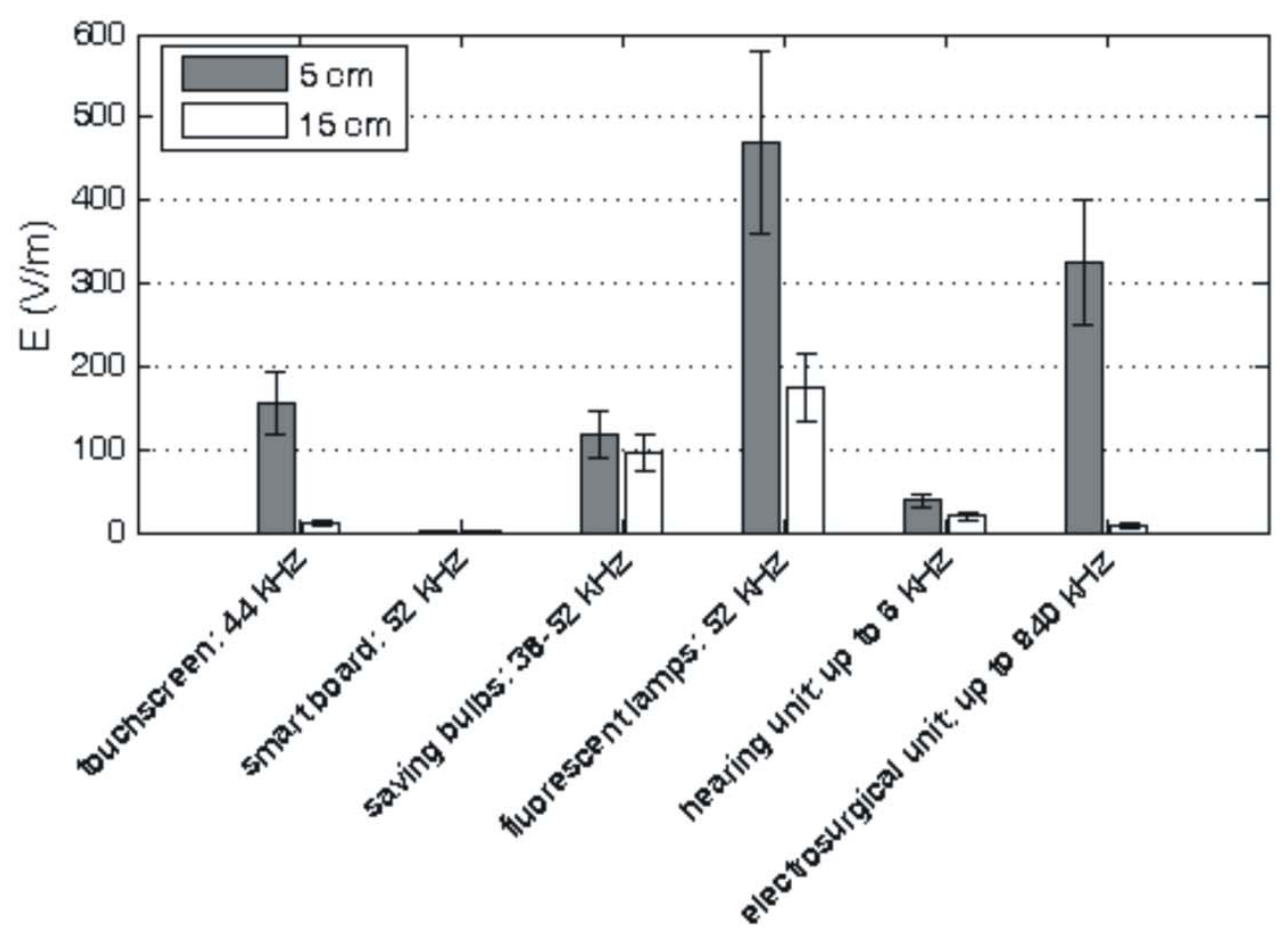

IF source

(a)

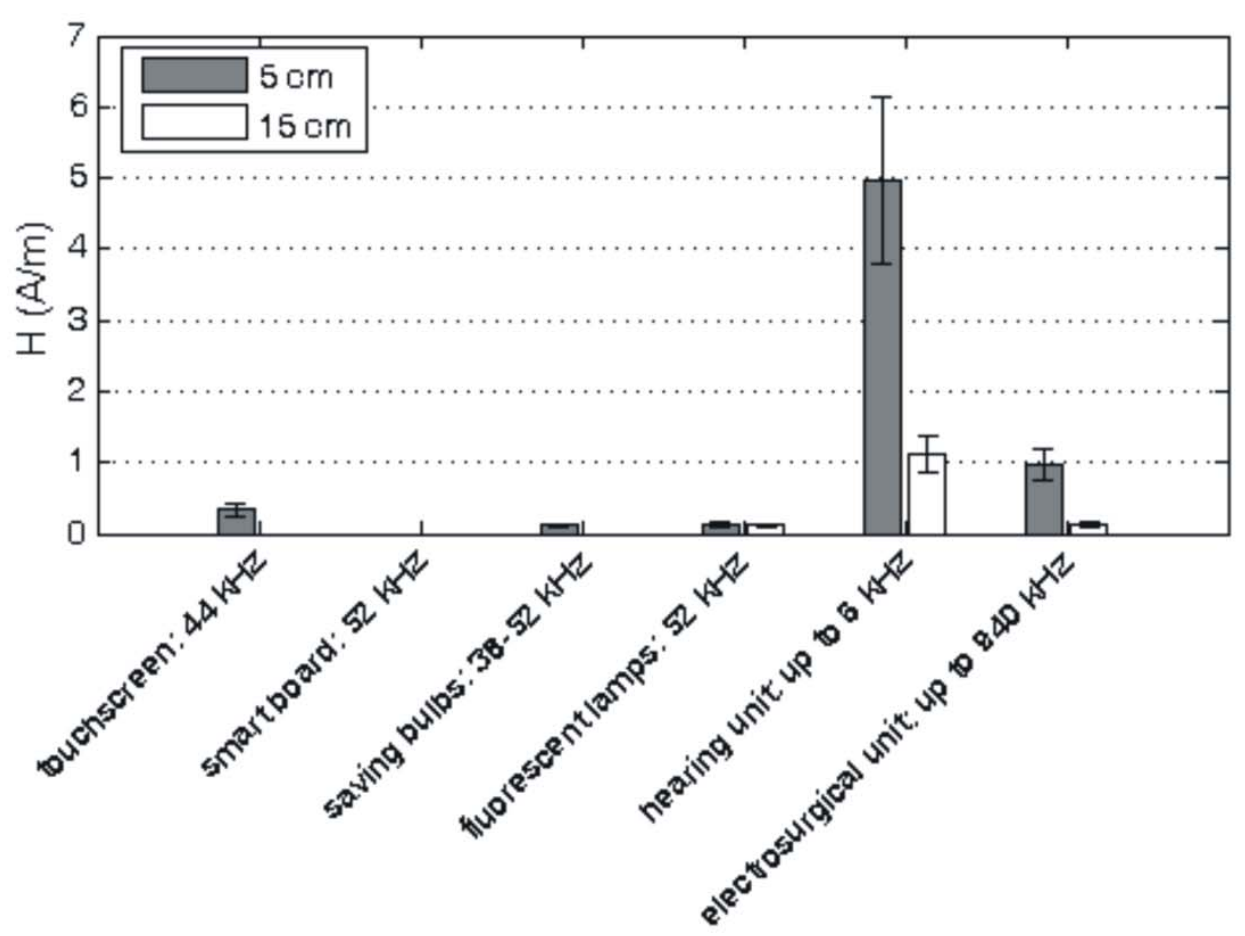

IF source

(b)

Figure 1 


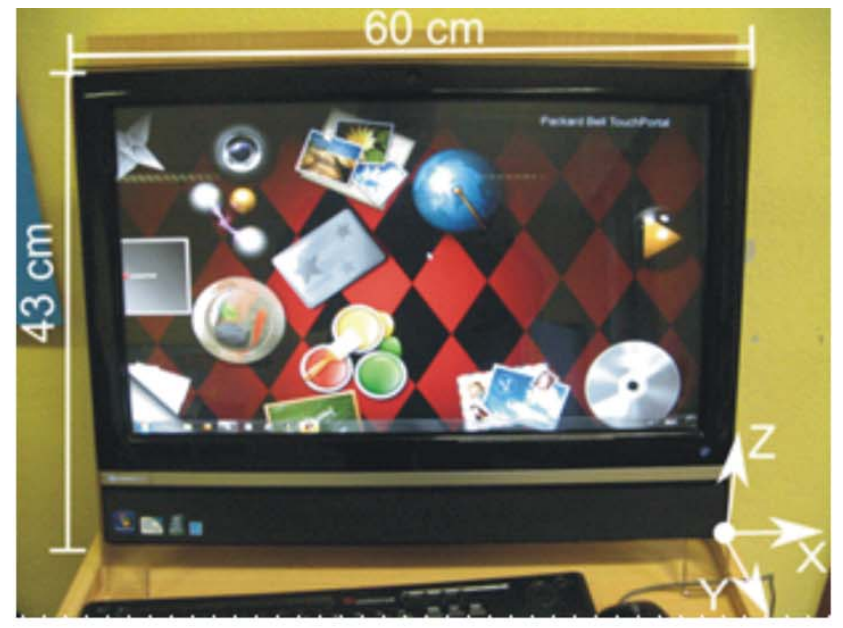

(a)

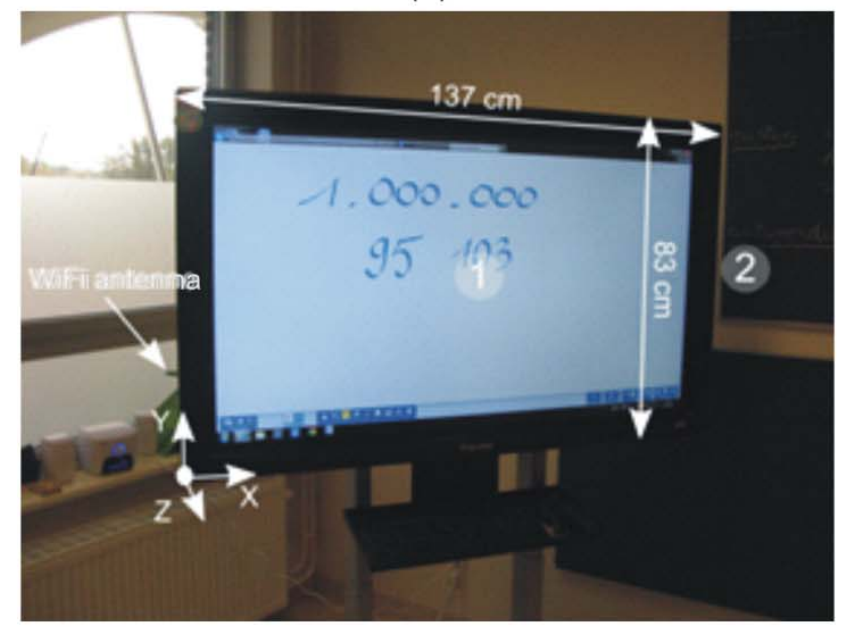

(b)

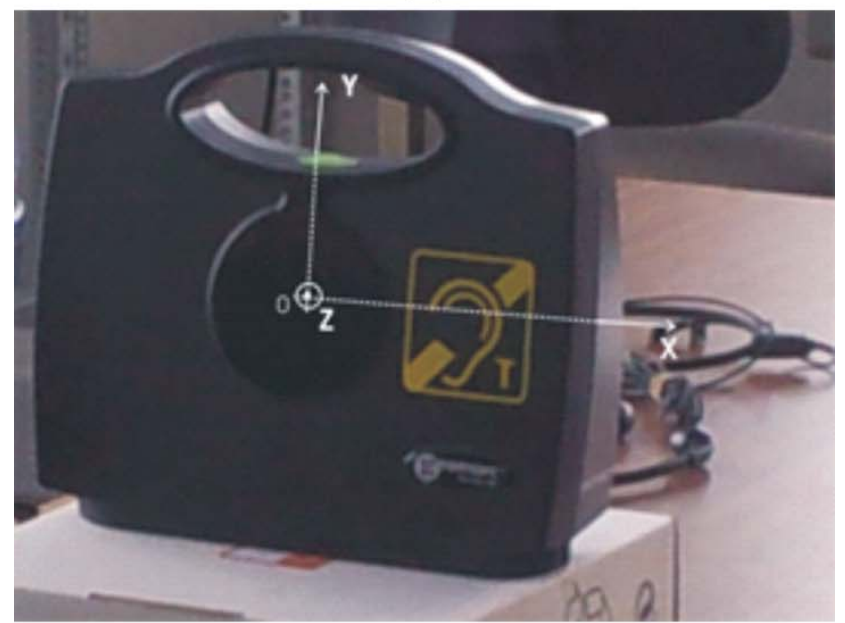

(c)

Figure 2 


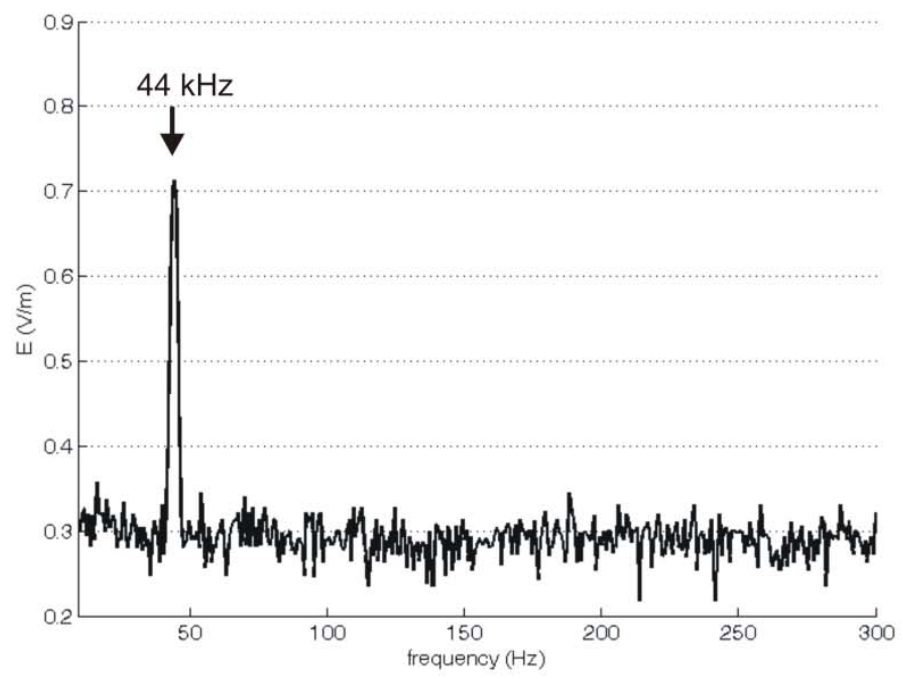

(a)

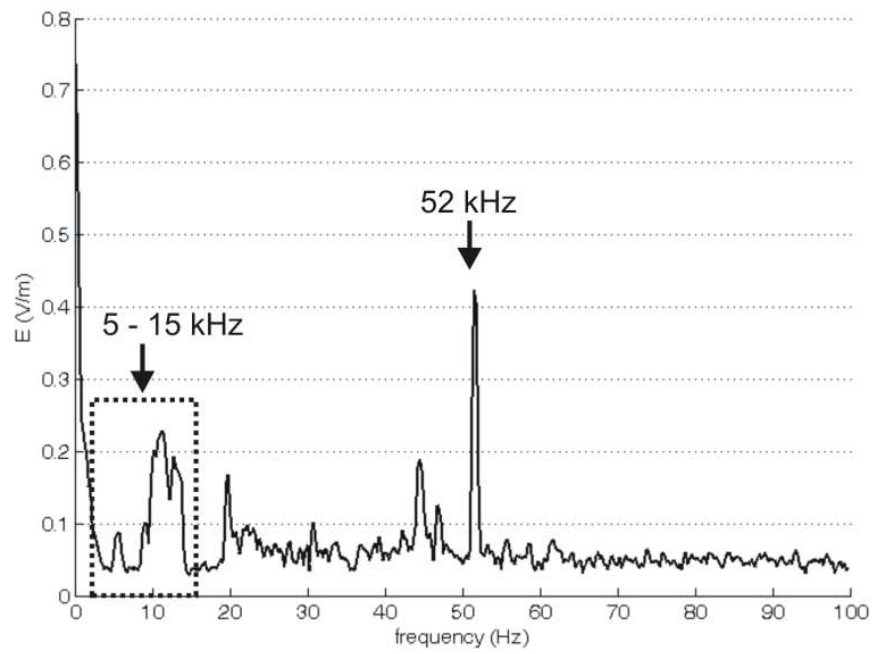

(b)

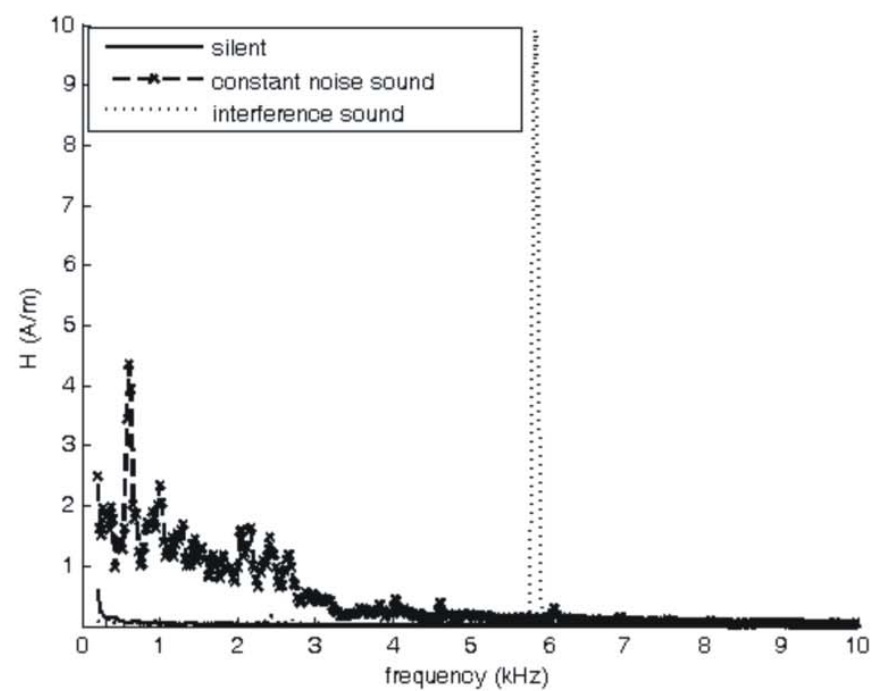

(c)

Figure 3 


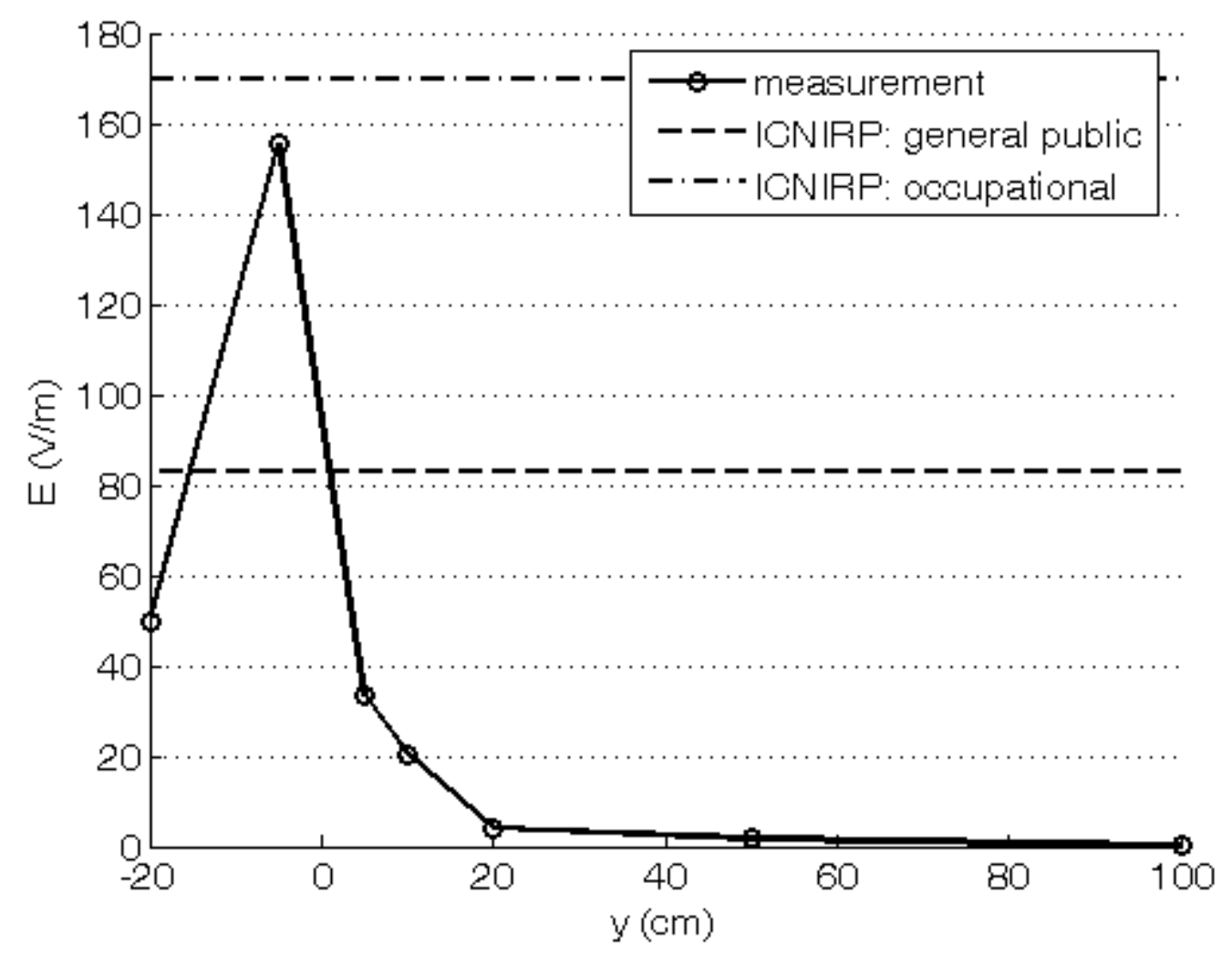

Figure 4 


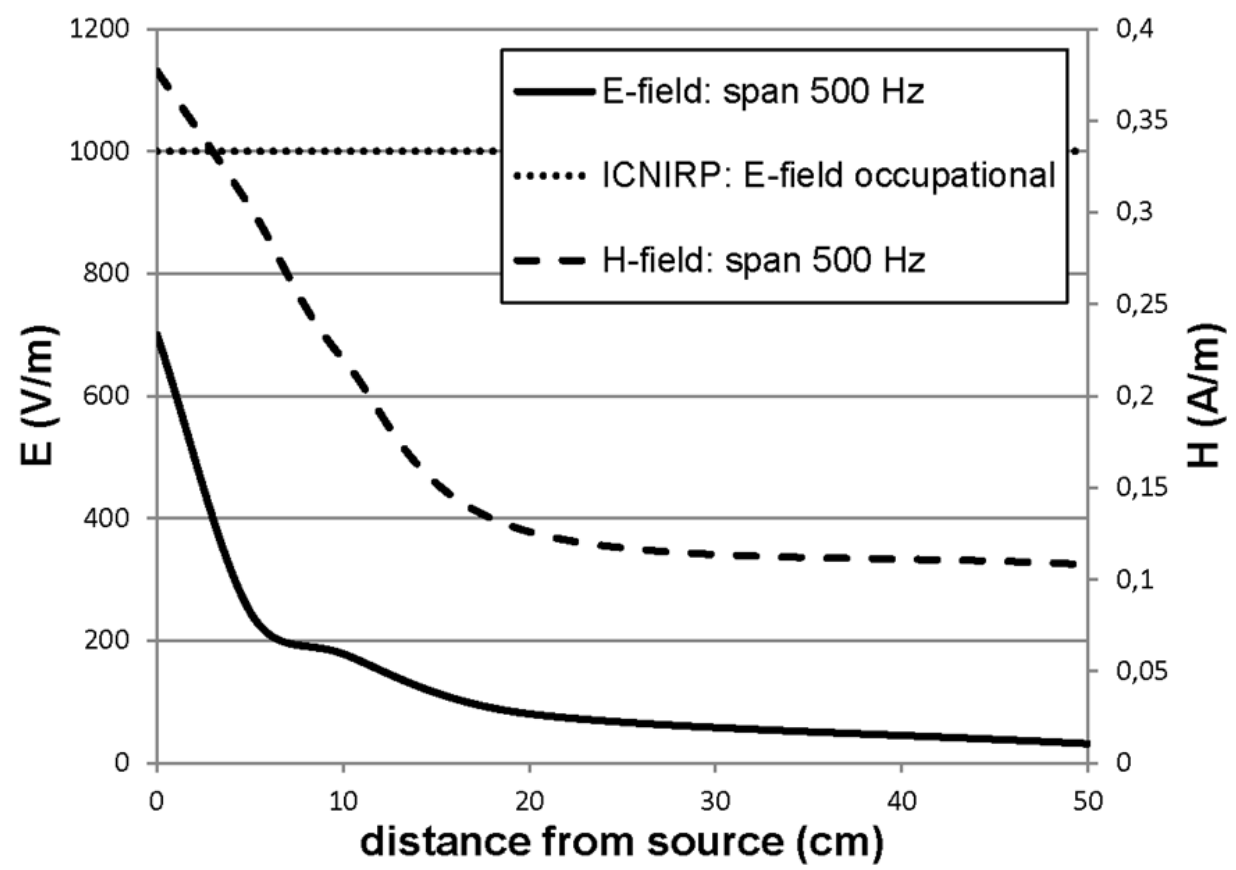

(a)

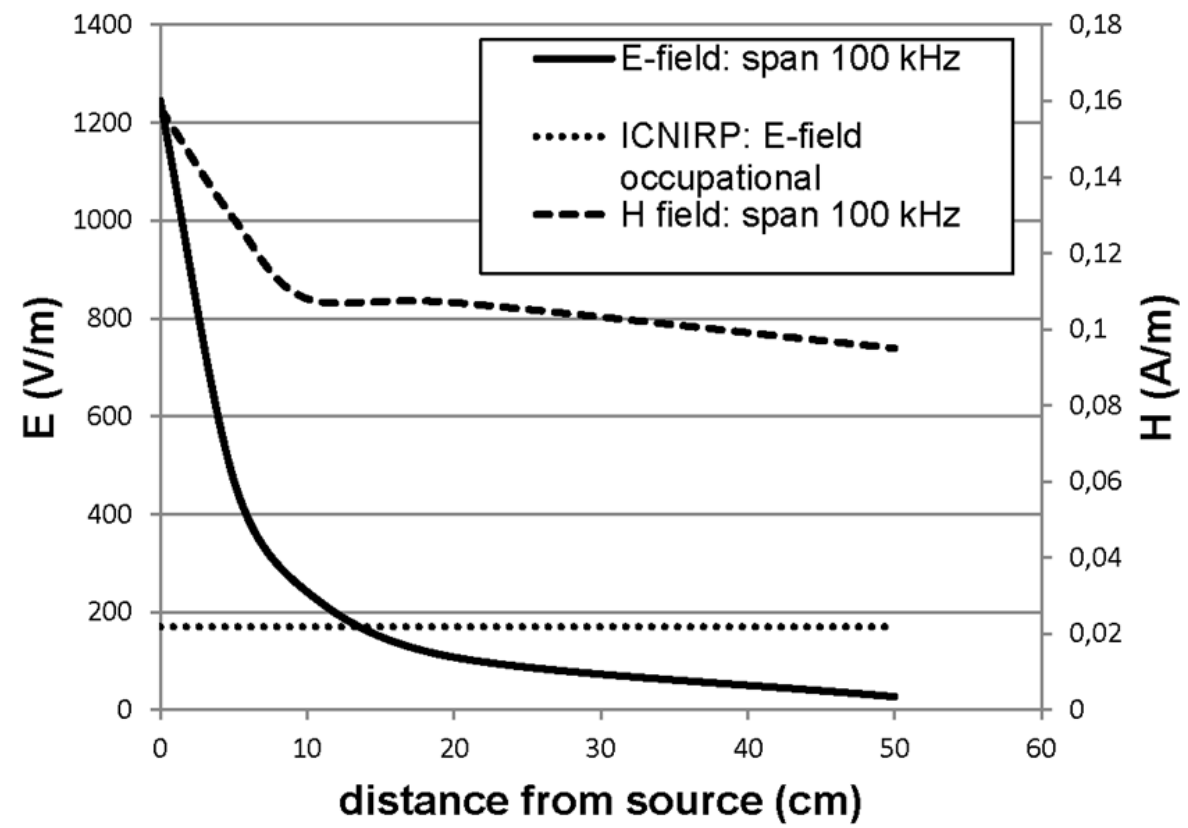

(b)

Figure 5 


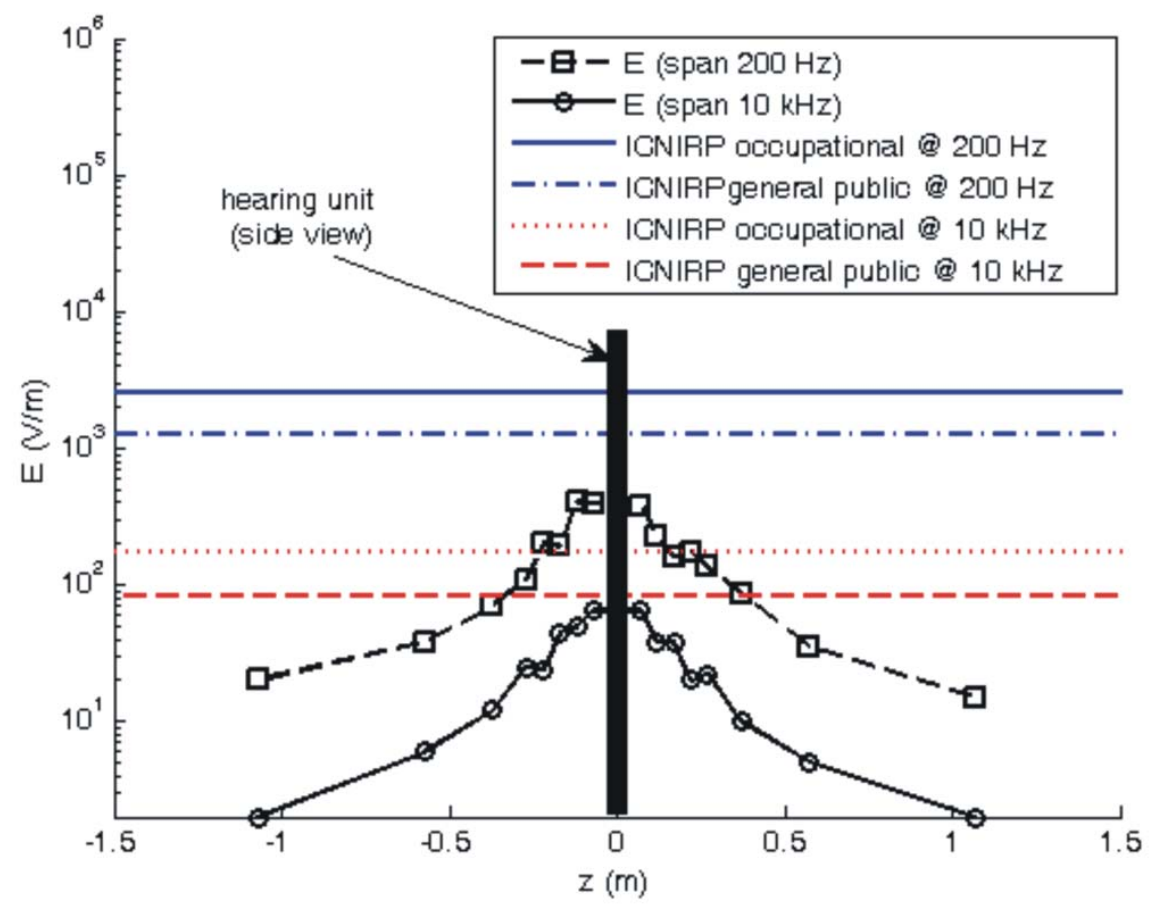

(a)

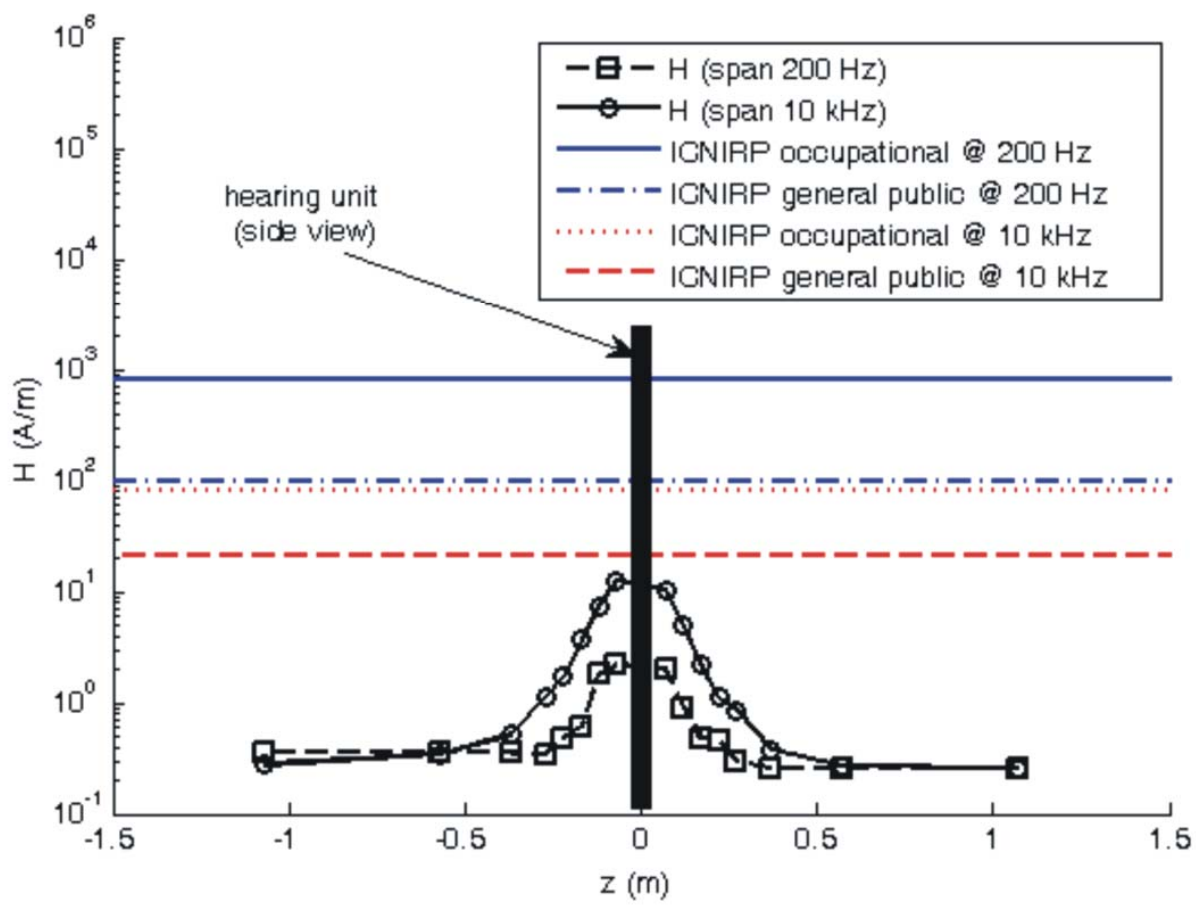

(b)

Figure 6 